\title{
A new proposal for laparoscopic left colectomy in a rat model ${ }^{1}$
}

\author{
Leonardo de Castro DurãesI, Eliana Ferreira Ribeiro Durães ${ }^{\text {II }}$, Pedro Felipe Silva de Freitas ${ }^{\text {III }}$, Felipe Augusto Neves Oliveira de \\ Carvalho ${ }^{\text {III }}$, Sérgio Andurte Carvalho ${ }^{\text {III }}$, João Batista de Sousa ${ }^{\text {IV }}$ \\ IFellow PhD degree, Postgraduate Program in Medical Sciences, Medical School, UnB, Brasilia-DF, Brazil. Design, intellectual and scientific content \\ of the study; acquisition and interpretation of data; statistical analysis; manuscript writing; critical revision.

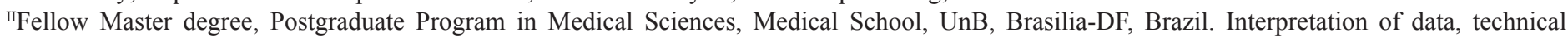 \\ procedures, statistical analysis, critical revision.

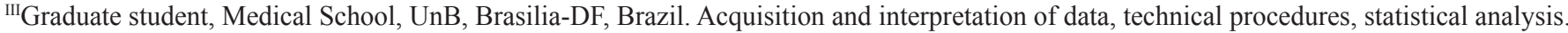 \\ ${ }^{\text {IV }} \mathrm{PhD}$, Associate Professor of Surgery, Medical School, UnB, Brasilia-DF, Brazil. Design, intellectual and scientific content of the study; interpretation \\ of data; technical procedures; manuscript writing; critical revision.
}

\begin{abstract}
PURPOSE: To evaluate the feasibility and safety of a new technique for laparoscopic segmental colectomy and primary anastomosis in the left colon of rats.

METHODS: Thirty rats were randomly assigned to three groups of ten animals each. All animals underwent segmental resection of the left colon and end-to-end anastomosis. In Group I, the animals underwent laparoscopic surgery with carbon dioxide pneumoperitoneum at a pressure of $5 \mathrm{mmHg}$. In Group II, the animals underwent pneumoperitoneum with carbon dioxide at a pressure of $12 \mathrm{mmHg}$. In Group III, the control group, the animals underwent open surgery. All animals were reopened on the 7th postoperative day and were evaluated for peritonitis, abscesses, anastomotic dehiscence and bowel obstruction, and the anastomosis bursting pressure was measured. RESULTS: No obstructions, peritonitis or abscesses were found in any of the animals. An animal in Group I exhibited a blocked anastomosis leakage. The average anastomosis bursting pressure in the 30 animals was $187.02 \pm 68.35 \mathrm{mmHg}$. There was no significant difference in the anastomosis bursting pressure among the groups $(\mathrm{p}=0.503)$

CONCLUSION: The laparoscopic experimental model was feasible and safe for segmental colectomy and anastomosis of the left colon in rats.
\end{abstract}

Key words: Laparoscopy. Colectomy. Colon. Anastomosis, Surgical. Rats. 


\section{Introduction}

Laparoscopic surgery has contributed great advances to the current surgical practice because of its advantages over open surgery, including shorter hospital stays, less postoperative pain, faster return to work, faster return of intestinal motility and better aesthetic results. The numerous benefits have led to the rapid incorporation of laparoscopic surgery into the therapeutic surgical options ${ }^{1}$.

The first laparoscopic surgeries in the gastrointestinal tract were an appendectomy in 1983 and a cholecystectomy in $1987^{2}$.

In 1990, Jacobs performed the first video-laparoscopic ${ }^{3}$ colectomies. The COST (Clinical Outcomes of Surgical Therapy) study in 2004 demonstrated that the use of laparoscopic colectomy in colon cancer showed similar oncological results to the results obtained in open surgery and provided better postoperative outcomes $^{4}$. The laparoscopic procedure was widely used and accepted in colorectal surgical practice.

The increasing number of colorectal laparoscopic surgeries increased the need for animal models to study the effects of pneumoperitoneum during colorectal surgery. Dogs and pigs were the first animals used in studies of laparoscopic surgery, but other animal models were soon sought as a result of the difficulties and cost associated with the use of dogs and pigs.

The rat is a classic animal model used in research, because rats are easy to standardize by race, sex and weight; are genetically and physiologically similar to each other; exhibit good resistance to infections; have low cost and easy maintenance; and have a well-characterized anatomy.

The aim of this study was to evaluate the feasibility and safety of a new model for laparoscopic segmental colectomy and primary anastomosis in the left colon of rats.

\section{Methods}

This study was performed at Experimental Surgery Laboratory of the Surgical Clinical Area, School of Medicine, University of Brasilia (UnB).

The research protocol was approved by the Ethics Committee on Animal Use of the Institute of Biological Sciences, UnB. The experimental procedures were performed in accordance with the guidelines of the Brazilian College of Animal Experimentation.

The study included 30 Wistar rats (Rattus norvegicus), which were fasted 12 hours prior to surgery with free access to water. All animals were sacrificed on the 7th postoperative day and underwent a laparotomy to examine the peritoneal cavity and test the anastomosis bursting pressure.

The weights of the animals were measured immediately before the operations on an electronic scale (model AS5500, Marte ${ }^{\circledR}$ Scales and Precision Equipment; Sao Paulo, Brazil).

\section{Experimental design}

The 30 rats were randomly assigned to three groups of ten animals each. In Group I, the animals underwent laparoscopic surgery with carbon dioxide pneumoperitoneum at a pressure of $5 \mathrm{mmHg}$. In Group II, the animals underwent pneumoperitoneum with carbon dioxide at a pressure of $12 \mathrm{mmHg}$. In Group III, the control group, the animals underwent open surgery.

\section{Anesthetic technique}

The animals were anesthetized with an intramuscular injection of xylazine at a dose of $5 \mathrm{mg} / \mathrm{kg}$ and ketamine hydrochloride at a dose of $25 \mathrm{mg} / \mathrm{kg}$. During the operation, additional doses of anesthesia were administered as needed.

\section{Operative technique}

After shaving the abdominal region, each animal was placed supine on a wooden board with its appendages secured with tape bandages. Antisepsis of the skin was achieved with an alcoholic solution of polyvinylpyrrolidone iodine.

In Groups I and II, a veress needle was introduced intraperitoneally at the midline $2 \mathrm{~cm}$ below the umbilicus. A silicone hose attached to a laparoscopic insufflator (Karl Storz ${ }^{\square}$ ) was coupled to the needle to initiate the pneumoperitoneum with a carbon dioxide gas flow of $1 \mathrm{~L} / \mathrm{min}$ at a pressure of $5 \mathrm{mmHg}$ (Group I) or $12 \mathrm{mmHg}$ (Group II).

A median incision was made $0.5 \mathrm{~cm}$ below the xiphoid process measuring $0.7 \mathrm{~cm}$ in length, and a $7 \mathrm{~mm}$ trocar was introduced. A $7 \mathrm{~mm}$ laparoscope was introduced into the peritoneal cavity, which was coupled to a processor Endoview $^{\circledR}$ - Recife, PE), light source (Endoview ${ }^{\circledR}$ - Recife, PE) and monitor $\left(\right.$ Sony $\left.{ }^{\circledR}\right)$, and laparoscopy of the entire cavity was performed. The inflator hose was switched to the supraumbilical trocar. A $5 \mathrm{~mm}$ trocar was introduced under direct vision at the area where the veress needle puncture was held (Figure 1). 


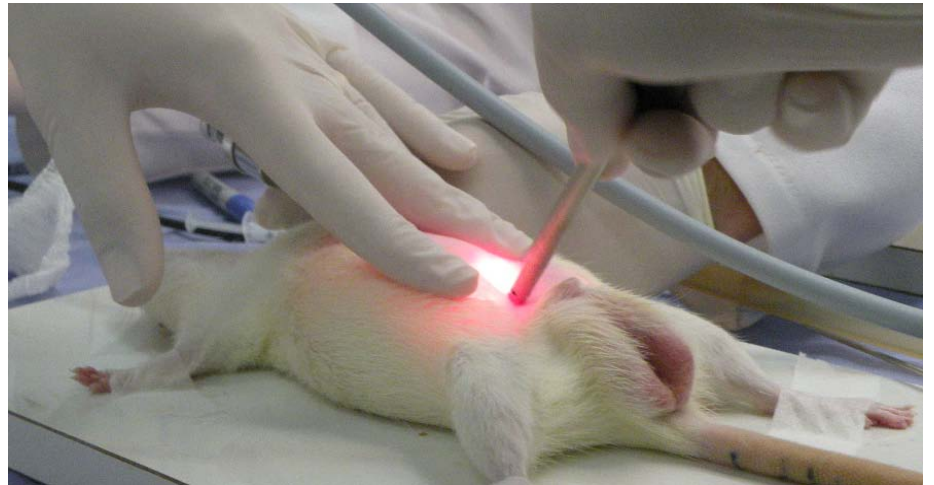

FIGURE 1 - Introduction of the $5 \mathrm{~mm}$ trocar $2 \mathrm{~cm}$ below the umbilicus under direct vision.

After the introduction of the infraumbilical trocar, a 5 $\mathrm{mm}$ Maryland forceps $\left(\mathrm{Edlo}^{\circledR}\right)$ was inserted to manipulate and identify the abdominal structures.

The peritoneal reflection was identified laparoscopically. After 60 minutes of pneumoperitoneum, the left colon was grasped with $5 \mathrm{~mm}$ forceps $3 \mathrm{~cm}$ above the peritoneal reflection (Figure 2).

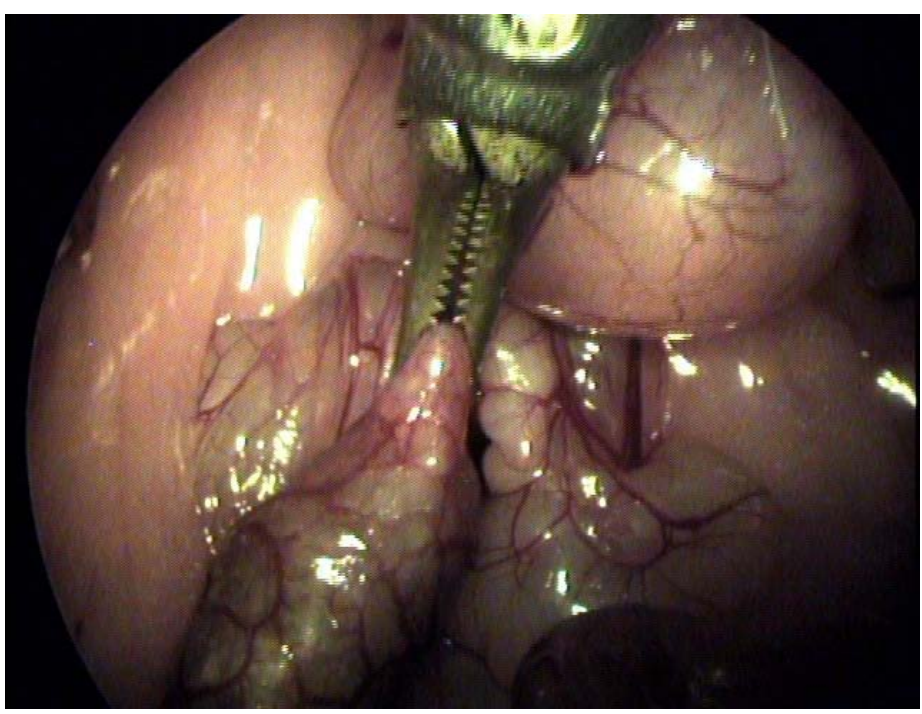

FIGURE 2 - Identification and apprehension of the left colon near the peritoneal reflection under laparoscopic vision.

The pneumoperitoneum was reversed, and the colonic segment was removed from the peritoneal cavity (Figure 3 ).

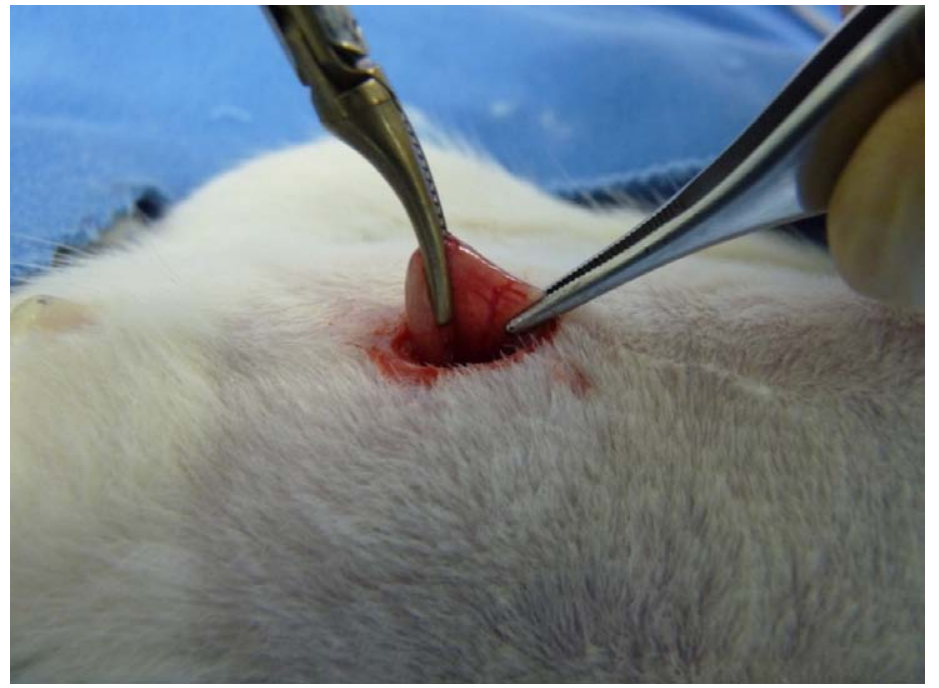

FIGURE 3 - Externalization of the left colon segment through the trocar incision below the umbilicus.

We performed resection of a $1 \mathrm{~cm}$ colonic segment using straight scissors.

The colonic transit was reconstructed with an end-to-end anastomosis in a single plane using a running suture that included all the layers of the intestinal wall using 6-0 polypropylene with a $1.3 \mathrm{~cm}$ cylindrical needle (Brasuture ${ }^{\circledR}$, Sao Sebastiao da Grama, SP, Brazil) (Figure 4).

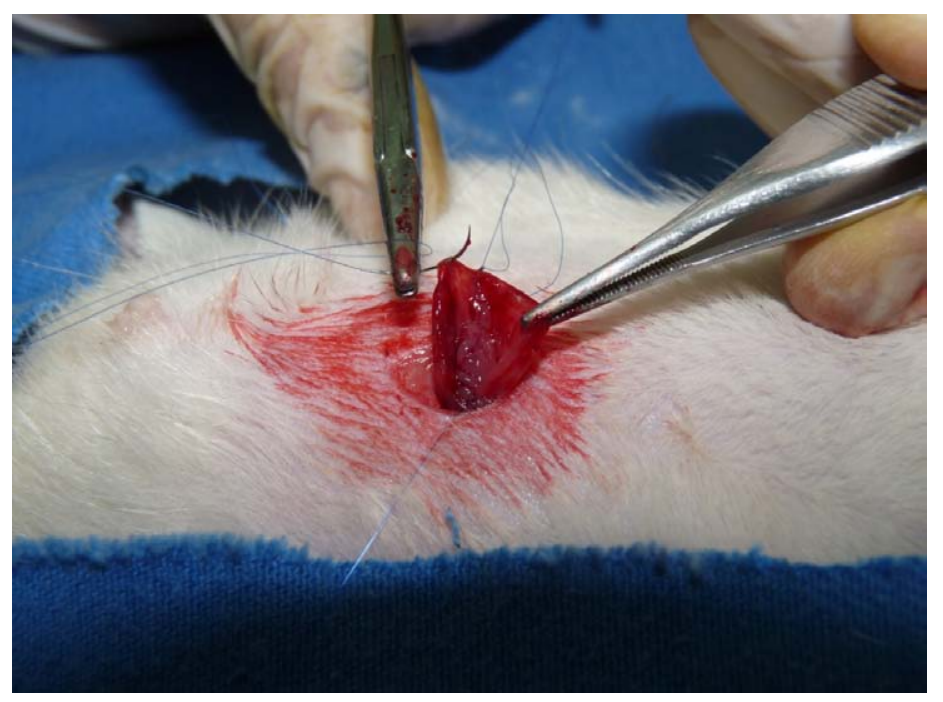

FIGURE 4 - End-to-end colonic anastomosis with a 6.0 polypropylene running suture.

After the colonic transit was reconstructed, the infraumbilical trocar was reintroduced, and the pneumoperitoneum was reinitiated at the same initial pressure. After $30 \mathrm{~min}$, the pneumoperitoneum was reversed, the trocars were removed, and the synthesis of the incisions was made. The wounds in the abdominal wall were closed in two layers: the 1st layer included 
the peritoneum, muscle and aponeurosis with running sutures, and the 2nd layer included the subcutaneous tissue and skin, using 5.0 polypropylene with a $1.5 \mathrm{~cm}$ cylindrical needle $\left(\right.$ Brasuture $^{\circledR}$, Sao Sebastiao da Grama, SP, Brazil).

In the control group, a midline $4 \mathrm{~cm}$ incision was made, which ended approximately $1 \mathrm{~cm}$ from the external genitalia of the animal. After $60 \mathrm{~min}$, a colonic segment was resected between 2.5 and $3.5 \mathrm{~cm}$ from the peritoneal reflection. An end-to-end anastomosis of the colon was held in the same manner described for Groups I and II. The animals were maintained under anesthesia for another $30 \mathrm{~min}$ before closure of the abdominal wall in two layers.

\section{Postoperative evaluation}

After recovery from anesthesia, the animals were placed in cages with water and food ad libitum. Autopsies were performed on the animals that died to determine the possible death cause, and the animals were replaced.

\section{Reoperation and postoperative analysis}

All animals from the three groups were reopened on the 7 th postoperative day. The weight of each animal was measured and recorded immediately before anesthesia was induced, and anesthesia was maintained using the previously described technique. A xipho-pubic midline incision was made to allow complete visualization of the abdominal cavity and examination for signs of peritonitis, abscess, anastomotic leakage or bowel obstruction.

\section{Bursting pressure}

A Z.10.RG (Zürich) register gauge was used to determine the bursting pressure.

With the anastomosis in situ, an incision was made in the colon approximately $5 \mathrm{~cm}$ proximal to the anastomosis. A urethral $10 \mathrm{Fr}$ tube was introduced $1 \mathrm{~cm}$ intraluminally and fixed with 2.0 silk thread. Antegrade colonic lavage was performed with a $0.9 \%$ saline solution followed by careful slow air insufflation to remove feces. The superior rectus was carefully dissected to maintain all adhesions to the anastomosis and ligated with 2.0 silk to close the intestinal lumen.

A 3-way circuit was coupled to the urethral probe, the register gauge and the compressed air cylinder. Airflow of $0.5 \mathrm{~L} /$ min was injected into the circuit until rupture of the anastomosis.
The maximum pressure was recorded at the time of the rupture (Figure 5).

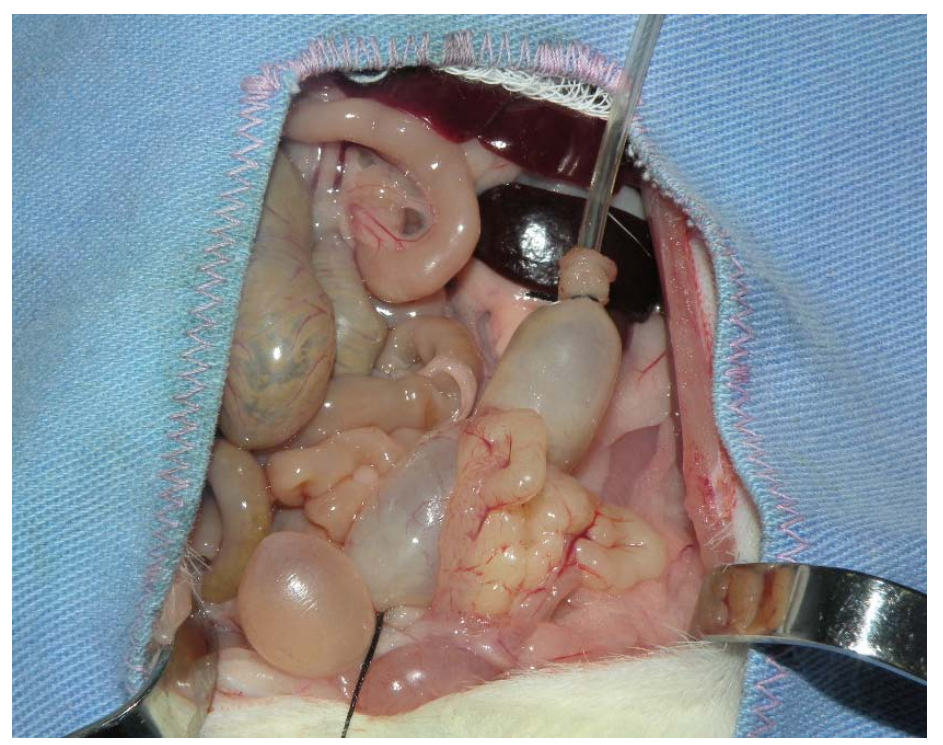

FIGURE 5 - Left colon inflated with air in the anatomical position with its adhesions to determine the bursting pressure.

\section{Statistical analysis}

The results were statistically analyzed using SPSS ${ }^{\circledR} 20.0$ software (Special Package for Social Sciences ${ }^{\circledR}$ ) and Microsoft Excel $^{\circledR}$.

Fisher's exact test was performed to analyze deaths and intraoperative findings.

Analysis of variance (ANOVA) and Student's t-test for paired samples were used to compare the changes between the initial weights and the weights on the $7^{\text {th }}$ postoperative day.

ANOVA was also used to compare the anastomosis bursting pressures among the three groups.

\section{Results}

\section{Deaths}

Among the 30 operated animals, two animals in Group II died during the experimental period. Both animals died on the $2^{\text {nd }}$ postoperative day. Autopsies were performed, but the cause of death could not be identified. The anastomoses remained intact in the deceased animals. Although the deaths occurred in the same group, there was no significant difference in the number of deaths among the groups using the Fisher exact test $(p=0.310)$. Both animals were replaced. 


\section{Animals'weights}

The initial weight in the 30 animals ranged from $244 \mathrm{~g}$ to $419.9 \mathrm{~g}$ (mean $336.44 \mathrm{~g}$ ), and the weight on the day of euthanasia ranged from $220 \mathrm{~g}$ to $416.1 \mathrm{~g}$ (mean $311.55 \mathrm{~g}$ ). The average weight was lower on the day of euthanasia compared with the initial weight $(p<0.001)$. The weight difference was compared within each group (Group I, p = 0.039; Group II, $\mathrm{p}<0.001$; and Group III, $p=0.001)$. There was no difference in the weight changes among the groups $(\mathrm{p}=0.131)$ (Figure 6).

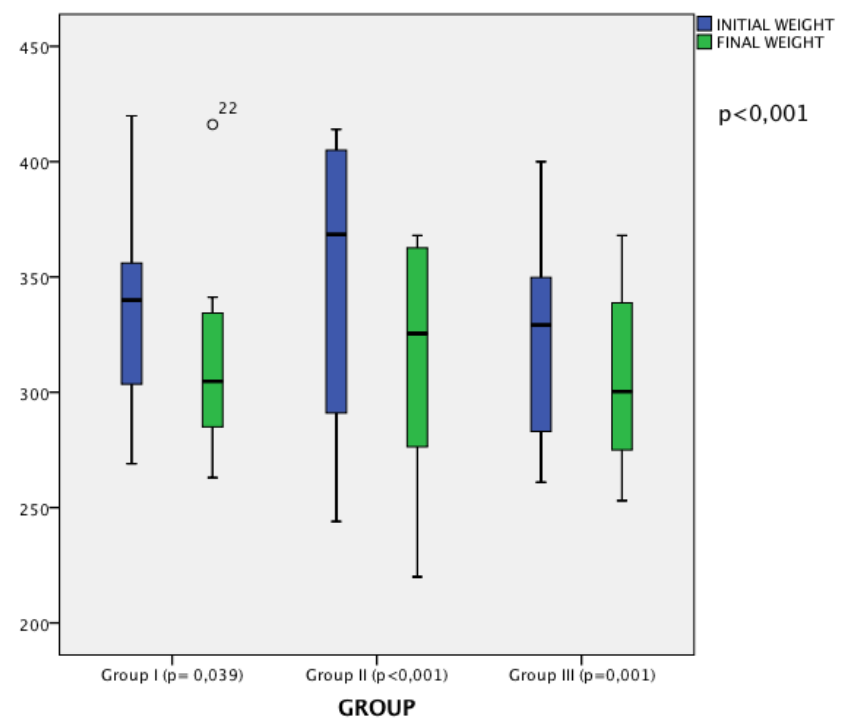

FIGURE 6 - Median and interquartile values and ranges of the animal weights on the day of surgery and the day of euthanasia for the three groups.

\section{Intraoperative findings}

Upon reopening on the 7 th postoperative day, an anastomotic leakage blocked by the omentum was identified in one animal from Group I. There was no significant difference among the groups using the Fisher exact test $(p=1)$. No cases of free anastomotic leakage with the presence of feces in the abdominal cavity were observed upon reopening.

We did not observe intestinal obstructions, peritonitis or abscesses during the follow-up operation.

\section{Bursting pressure}

The bursting pressure in the 30 animals ranged from 0 $\mathrm{mmHg}$ to $314 \mathrm{mmHg}$ with an average of $187.02 \mathrm{mmHg}$, median of $197.85 \mathrm{mmHg}$ and standard deviation of $68.35 \mathrm{mmHg}$.

One animal in Group I showed a blocked anastomotic leakage and presented a bursting pressure of $0 \mathrm{mmHg}$.
There was no significant difference in the bursting pressure among the groups $(\mathrm{p}=0.503)$ (Figure 7).

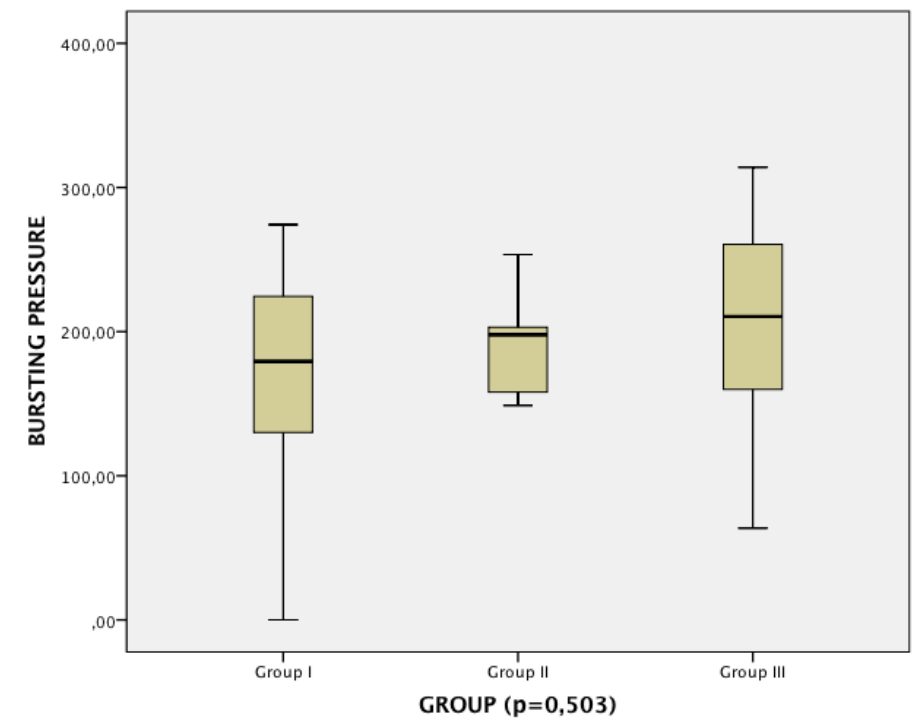

FIGURE 7 - Median and interquartile values and ranges of the anastomosis bursting pressures for the three groups. Values in $\mathrm{mmHg}$.

\section{Discussion}

As a result of the increasing interest in laparoscopic surgery, the physiological effects of gas pressure on the abdominal organs have been increasingly studied. In colorectal surgery, the effects of pneumoperitoneum on the colorectal anastomosis need to be evaluated.

Experimental rat models of laparoscopic surgery have been described previously ${ }^{5,6}$. However, laparoscopic surgeries, especially intracorporeal anastomosis, are difficult to perform in rat models, which require special materials for laparoscopic microsurgery $^{7-9}$.

The proposed model uses common laparoscopic surgery materials and simulates the conditions that humans are subjected to in laparoscopic left colectomy. In humans undergoing this operation, pneumoperitoneum is performed for visualization of abdominal structures, dissection, ligation of the mesenteric vessels and release of the colon. After the pneumoperitoneum is reversed, the released colon is exteriorized through a small abdominal incision. The colonic resection is held, and anastomosis can be performed or prepared. Pneumoperitoneum is repeated for bleeding control and anastomosis if it was not done yet. The same steps were followed in the proposed animal model.

Anteriorly approaching the left colon of rats is difficult. The present model allows the rectum, sigmoid and extracorporeal anastomosis to be approached easily.

We chose pressures of 5 and $12 \mathrm{mmHg}$ for the 
pneumoperitoneum because $5 \mathrm{mmHg}$ in the rat simulates the pressure of $12 \mathrm{mmHg}$ used in humans, and $12 \mathrm{mmHg}$ is the most commonly used pressure in laparoscopic surgery ${ }^{10}$.

This model study was tested in 20 rats. Two deaths occurred on postoperative day 2 without apparent cause, and no signs of anastomotic leakage or peritonitis were observed during the autopsy.

At postoperative day 7, there was no difference between the groups undergoing laparoscopic surgery and the control group.

Bursting pressure was analyzed in situ without removing the colon. The adhesions at the anastomosis are maintained to provide a more reliable physiological condition comparable with the conditions in human colorectal surgery. There was no difference between the results of the bursting pressures of the groups undergoing pneumoperitoneum with carbon dioxide at pressures of 5 and $12 \mathrm{mmHg}$ and the control group. The absence of a difference was expected and validated the experimental model.

\section{Conclusion}

The experimental rat model for laparoscopic colorectal surgery was feasible and safe and provides a significant contribution to scientific research in experimental colorectal surgery, particularly for the study of intestinal anastomosis healing.

\section{References}

1- Lacy AM, Delgado S, Castells A, Prins HA, Arroyo V, Ibarzabal A, Pique JM. The long-term results of a randomized clinical trial of laparoscopy-assisted versus open surgery for colon cancer. Ann Surg. 2008;248(1):1-7.

2- Dubois F, Berthelot G, Levard H. Laparoscopic cholecystectomy: historic perspective and personal experience. Surg Laparosc Endosc. 1991;1(1):52-7.

3- Jacobs M, Verdeja JC, Goldstein HS. Minimally invasive colon resection (laparoscopic colectomy). Surg Laparosc Endosc. 1991;1(3):144-50.

4- Clinical Outcomes of Surgical Therapy Study Group. A comparison of laparoscopically assisted and open colectomy for colon cancer. $\mathrm{N}$ Engl J Med. 2004;13:350(20):2050-9.

5- $\quad$ Meyer F, Ioshii SO, Chin EWK, Esser DM, Marcondes RT, Patriani AH, Pimpão B de F. Laparoscopic partial nephrectomy in rats. Acta Cir. Bras.2007;22(2):152-6.

6- Silva JJ, Silva AL, Paulo DNS. Subtotal laparoscopic splenectomy in rats with preservation of the inferior pole. Acta Cir. Bras. 2011;26(1):44-50.

7- Berguer R, Gutt CN. Laparoscopic colon surgery in a rat model. A preliminar report. Surg Endosc. 1994;8:1195-7.

8- Gutt CN, Riemer V, Brier C, Berguer R, Paolucci V. Standardized technique of laparoscopic surgery in the rat. Dig Surg. 1998;15:1359.

9- Tytgat S, Rijkers GT, Van Der Zee DC. The influence of the $\mathrm{CO}_{2}$ pneumoperitoneum on a rat model of intestinal anastomosis healing. Surg Endosc. 2012;26:1642-7.

10- Avital S, Itah R, Szomstein S, Rosenthal R, Inbar R, Sckornik Y, Weinbroum A. Correlation of $\mathrm{CO} 2$ pneumoperitoneal pressures between rodents and humans. Surg Endosc. 2009;23(1):50-4.

\section{Correspondence:}

Leonardo de Castro Durães

UnB-Campus Universitário Darcy Ribeiro

Faculdade de Medicina-Laboratório de Cirurgia Experimental 70910-900 Brasília - DF Brasil

Tel.: (55 61)8546-9595

leonardoduraes@yahoo.com.br

Received: December 18, 2012

Review: February 20, 2013

Accepted: March 19, 2013

Conflict of interest: none

Financial source: none

${ }^{1}$ Research performed at Experimental Surgery Laboratory, School of Medicine, University of Brasilia (UnB), Brazil. Part of $\mathrm{PhD}$ degree thesis, Postgraduate Program in Medical Sciences. Tutor: João Batista de Sousa. 